\title{
New sensor based on AgCl containing Iron Oxide or Zinc Oxide Nanoparticles for Chloride Determination
}

\author{
Ante Prkićl, ${ }^{1,}$, Tina Vukušić ${ }^{2}$, Ivana Mitar $^{3}$, Josipa Giljanović ${ }^{1}$, Vesna Sokol ${ }^{4}$, Perica Bošković3, \\ Miće Jakić, Andrea Sedlar ${ }^{1}$ \\ ${ }^{1}$ Department of Analytical Chemistry, Faculty of Chemistry and Technology, University of Split, \\ Ruđer Bošković 35, 21000 Split, Croatia. \\ ${ }^{2}$ Faculty of Chemistry and Technology, University of Split, Ruđer Bošković 35, 21000 Split, Croatia. \\ ${ }^{3}$ Department of Chemistry, Faculty of Science, University of Split, Ruđer Bošković 33, 21000 Split, \\ Croatia. \\ ${ }^{4}$ Department of Physical Chemistry, Faculty of Chemistry and Technology, University of Split, Ruđer \\ Bošković 35, 21000 Split, Croatia. \\ ${ }^{5}$ Department of Organic Technology, Faculty of Chemistry and Technology, University of Split, \\ Ruđer Bošković 35, 21000 Split, Croatia. \\ "E-mail: prkic@ktf-split.hr
}

doi: $10.20964 / 2019.01 .71$

Received: 13 September 2018 / Accepted: 23 October 2018 / Published: 30 November 2018

This work describes preparation and application of "homemade" chloride ISE enriched with iron oxides or zinc oxide nanoparticles. The prepared chloride ISE membrane was made of $\mathrm{AgCl}: \mathrm{Ag}_{2} \mathrm{~S}: \mathrm{PTFE}=$ 1:1:2 and $\mathrm{AgCl}: \mathrm{Ag}_{2} \mathrm{~S}: \mathrm{PTFE}=2: 1: 2$ enriched with mentioned nanoparticles in ratio 0.5-1.2 wt.\%. Prepared membranes were used for chloride determination in perchloric acid $(\mathrm{pH}=0-2)$ and acetic buffer ( $\mathrm{pH}=4-4.75)$. Due to the low method price, simplicity and a reasonably fast way of usage, it was considered as a possibility for chloride determination in high acid media. Two of prepared membranes (M1 and M4) have shown best characteristics. M1 showed linear response range for chloride between $2.0 \times 10^{-6}$ and $1 \times 10^{-1} \mathrm{~mol} \mathrm{~L}^{-1}$, with a detection limit of $2.24 \times 10^{-6} \mathrm{~mol} \mathrm{~L}^{-1}$ and potential change of 44.39 $\mathrm{mV}$ per decade. M4 showed linear response range for chloride between $4.2 \times 10^{-6}$ to $1 \times 10^{-1} \mathrm{~mol} \mathrm{~L}^{-1}$, limit of detection of $1.39 \times 10^{-6} \mathrm{~mol} \mathrm{~L}^{-1}$ with potential change of $24.79 \mathrm{mV}$ per decade at $\mathrm{pH}=0$.

Keywords: chloride, potentiometric, determination, "homemade" ion-selective electrode, nanoparticles

\section{FULL TEXT}


(C) 2019 The Authors. Published by ESG (www.electrochemsci.org). This article is an open access article distributed under the terms and conditions of the Creative Commons Attribution license (http://creativecommons.org/licenses/by/4.0/). 